\title{
Preliminary Assessment of Methane Concentration Variation Observed by GOSAT in China
}

\author{
Xiuchun Qin, ${ }^{1}$ Liping Lei, ${ }^{1}$ Zhonghua He, ${ }^{1}$ Zhao-Cheng Zeng, ${ }^{1,2}$ Masahiro Kawasaki, ${ }^{3}$ \\ Masafumi Ohashi, ${ }^{4}$ and Yutaka Matsumi ${ }^{3}$ \\ ${ }^{1}$ Key Laboratory of Digital Earth Science, Institute of Remote Sensing and Digital Earth, Chinese Academy of Sciences, \\ Beijing 100094, China \\ ${ }^{2}$ Institute of Space and Earth Information Science, The Chinese University of Hong Kong, Shatin 999077, Hong Kong \\ ${ }^{3}$ Nagoya University, Nagoya 890-0065, Japan \\ ${ }^{4}$ Kagoshima University, Kagoshima 464-8601, Japan \\ Correspondence should be addressed to Liping Lei; leilp@radi.ac.cn
}

Received 16 February 2015; Accepted 18 May 2015

Academic Editor: Xiaozhen Xiong

Copyright (C) 2015 Xiuchun Qin et al. This is an open access article distributed under the Creative Commons Attribution License, which permits unrestricted use, distribution, and reproduction in any medium, provided the original work is properly cited.

Atmospheric column-averaged methane $\left(\mathrm{XCH}_{4}\right)$ observations from GOSAT are analyzed to study the spatiotemporal variation of $\mathrm{XCH}_{4}$ in China. Furthermore, we investigate the driving mechanism of $\mathrm{XCH}_{4}$ spatiotemporal variations, especially for high $\mathrm{XCH}_{4}$ values shown over Sichuan Basin, by analyzing both the emission mechanism of rice planting process and the regional atmosphere dynamic transportation. The results indicate that spatially the Sichuan Basin presents a higher $\mathrm{XCH}_{4}$ concentration than other regions in China and is $17 \mathrm{ppb}$ higher than the paddy area in the same latitude zone. Seasonally, $\mathrm{XCH}_{4}$ in Sichuan Basin during rice harvest season is generally higher than that in early cultivation period. However, comparing to paddy area in the same latitude zone, Sichuan Basin shows a relatively higher $\mathrm{XCH}_{4}$ value during the winter of noncultivation period when the emissions from rice paddies are weak and surface air temperature is low. To further investigate the high $\mathrm{XCH}_{4}$ concentration during this low-emission period, we use the HYSPLIT model to simulate the atmosphere dynamic transport process, and the result suggests that the typical closed topography of Sichuan Basin, which may lead to $\mathrm{CH}_{4}$ accumulation and keep it from diffusion, is one possible reason for the high $\mathrm{XCH}_{4}$ value in winter.

\section{Introduction}

Atmospheric methane $\left(\mathrm{CH}_{4}\right)$ is one of the most important greenhouse gases, and the greenhouse effect generated by unit molecule of $\mathrm{CH}_{4}$ is about 23 times higher than that of atmospheric carbon dioxide $\left(\mathrm{CO}_{2}\right)$. Therefore, it will be more effective to reduce the $\mathrm{CH}_{4}$ emissions to mitigate the potential global warming than reducing $\mathrm{CO}_{2}$ emissions [1]. The World Meteorological Organization (WMO) indicated in the "Greenhouse Gas Bulletin" published on September 9, 2014, that, from the year 1990 to 2013, greenhouse effect had increased by $34 \%$ due to increasing concentrations of greenhouse gases such as $\mathrm{CO}_{2}$ and $\mathrm{CH}_{4}$. Global warming has become one of the most important global environmental issues nowadays. Therefore, analyses of the $\mathrm{CH}_{4}$ concentration variation and studies on its driving factors have drawn increasing attention. However, due to limited observation capabilities and understanding of $\mathrm{CH}_{4}$ sources and sinks, the underlying driving factors for the regional $\mathrm{CH}_{4}$ spatiotemporal variation are still unclear [2]. The increase of global atmospheric $\mathrm{CH}_{4}$ concentration is mainly due to agricultural activities, in which irrigated rice paddy is one of the most important sources [3]. China is the world's largest rice producer, accounting for about $22 \%$ of the rice planting area in the world and $37 \%$ of the global production. Therefore, studies of China's regional $\mathrm{CH}_{4}$ emissions and its driving factors are of importance to understand the regional and global carbon cycle and the changing climate.

Since 1983, WMO has established a global greenhouse gases reference network for continuous observation of atmospheric greenhouse gases, including $\mathrm{CH}_{4}$ concentration. However, due to the limited observation stations in many 
parts of the world, it is still difficult to comprehensively understand the global distribution and variation of $\mathrm{CH}_{4}$ $[4,5]$. Satellite remote sensing observation of atmospheric $\mathrm{CH}_{4}$ concentration, which provides continuous observations at the global scale, plays an increasingly important role in improving our understanding of the distribution of sources and sinks of $\mathrm{CH}_{4}$ and the carbon cycle $[6,7]$. To date, several satellites for observing $\mathrm{CH}_{4}$ had been launched, including Atmospheric Infrared Sounder (AIRS) on the EOS/Aqua platform [8], SCanning Imaging Absorption spectroMeter for Atmospheric CHartographY (SCIAMACHY) $[9,10]$, and the Greenhouse gases Observing SATellite (GOSAT) [11], and a lot of valuable observations have been obtained. Using AIRS data, Xiong et al. [12] investigated a strong enhancement of $\mathrm{CH}_{4}$ over South China region during the summer, July, August, and September, in the middle to upper troposphere, and its relationship with transport and local surface $\mathrm{CH}_{4}$ emission. Zhang et al. [13] discovered that the vertical distribution of $\mathrm{CH}_{4}$ concentration in the troposphere of China area decreases as the altitudinal increases. Moreover, seasonal $\mathrm{CH}_{4}$ concentration in the eastern and northern parts of China presents a double-peak variation, with the highest concentration in summer and the second highest in winter. Hayashida et al. [10] analyzed the relationship between rice paddy emission and $\mathrm{XCH}_{4}$ concentration in Southeast Asia using satellite data obtained by SCIAMACHY and found that there is a strong correlation between the two variables in Southeast Asia. Zhang et al. [13] showed that paddy $\mathrm{CH}_{4}$ emission is the major source of $\mathrm{CH}_{4}$ in China and found that the air temperature, normalized difference vegetation index (NDVI), and soil total nitrogen explain more than $75 \%$ of the $\mathrm{XCH}_{4}$ variation in China. Previous studies by $[10,12,13]$ also showed that a consistently high $\mathrm{CH}_{4}$ concentration is observed in the Sichuan Basin, including Chongqing and Sichuan regions in southwest China. These studies greatly improved the estimation of regional and national $\mathrm{CH}_{4}$ emissions as well as our understanding of the $\mathrm{CH}_{4}$ emission mechanism. However, most of previous studies focused on examining the correlation between the $\mathrm{CH}_{4}$ variation and emissions from rice paddies, while potential driving factors for $\mathrm{CH}_{4}$ variation, such as the atmospheric dynamic transport and influence from external sources, are not well analyzed, and therefore the underlying mechanism affecting the spatial and temporal distribution of $\mathrm{CH}_{4}$ has not been comprehensively understood. Moreover, the used satellite observations of $\mathrm{CH}_{4}$ concentration by most previous studies are primarily obtained from SCIAMACHY [12, 13], which was operational from March 2002 to April 2012. However, due to sensor problems that happened in the end of the year 2005, the SCIAMACHY observing instrument became unstable since 2006 [2]. The GOSAT, launched on January 23,2009 , is the world's first spacecraft dedicated to observing greenhouse gases, including $\mathrm{CO}_{2}$ and $\mathrm{CH}_{4}$ [14] GOSAT data has been widely used in many previous studies for studying $\mathrm{CO}_{2}[8,15-17]$, while studies on analyzing $\mathrm{CH}_{4}$ from GOSAT observations are still rare.

In this study, $\mathrm{XCH}_{4}$ observations from GOSAT, spanning from January 2010 to December 2013, are analyzed to study the spatiotemporal variation of $\mathrm{XCH}_{4}$ in China and its relationship with regional surface emissions. Furthermore, we investigate the driving mechanism of $\mathrm{XCH}_{4}$ spatiotemporal variations, especially for high $\mathrm{XCH}_{4}$ values shown over Sichuan Basin in southwest China, by combining the emission mechanism of rice planting process, the meteorology data, the surface emission data, and the regional atmosphere dynamic transportation.

\section{Study Area and Data}

2.1. Study Area. Figure 1 shows the study area of China land region, the Sichuan Basin, and the corresponding same latitude zone in the east for comparison of $\mathrm{XCH}_{4}$ variation. Sichuan Basin is located in the upper reaches of the Yangtze River, encompassing the eastern part of Sichuan province and most of Chongqing city, with an elevation of about 500 meters above the sea level. The basin has a close topography, in which the eastern, southern, and northern parts of the basin are surrounded by mountains, and to the western is Qinghai-Tibet Plateau, which makes it difficult for air flow diffusion. The summer season of the basin lasts for 4 to 5 months with rich rain and temperatures as high as 25 $29^{\circ} \mathrm{C}$ during the hottest month, which is suitable for rice growing and makes the basin one of China's five major riceproducing regions [18]. The paddy region in Sichuan Basin with elevation less than 1000 meters is chosen to be the study area. In addition, Yanting county $\left(105^{\circ} 27^{\prime} \mathrm{E}, 31^{\circ} 16^{\prime} \mathrm{N}, \sim 420 \mathrm{~m}\right.$ in altitude), where we conducted ground-based observation of $\mathrm{XCO}_{2}$ and $\mathrm{XCH}_{4}[19,20]$, and Yueyang city $\left(116^{\circ} 42^{\prime} \mathrm{E}\right.$, $43^{\circ} 38^{\prime} \mathrm{N}, \sim 40 \mathrm{~m}$ in altitude), which is located between Hunan province and Hubei province in the same latitude paddy zone with Yanting, as shown in Figure 1, are chosen to be centers of the atmospheric molecule trajectory simulation.

\subsection{Data Collection}

(1) Satellite Data. In this study, 3-year GOSAT $\mathrm{XCH}_{4}$ Level 2 data (Version 02.XX) for General User (GU) from the year 2010 to 2012 are collected. $\mathrm{XCH}_{4}$ data are retrieved using the spectra observed from Thermal And Near-infrared Sensor for carbon Observation Fourier Transform Spectrometer (TANSO-FTS) with an orbiting period of 3 days. The nadir footprint of the instrument has a diameter of about $10.5 \mathrm{~km}$ at sea level [21]. Compared to early versions, these $02 . \mathrm{xx}$ version $\mathrm{XCH}_{4}$ data were improved by identifying and correcting the error characteristics in retrieval, such as handling of aerosol scattering [22] which has a big impact on the GOSAT retrieval accuracy. The comparison result with data of the Total Carbon Column Observing Network (TCCON) shows the bias and standard deviation of the GOSAT $\mathrm{XCH}_{4}$ data are -5.9 and $12.6 \mathrm{ppb}$, respectively [22]. Our ground measurement results implemented at Yanting Station using optical spectrum analyzer (OSA) $[19,20]$ for October-November of 2013 present $24 \mathrm{ppb}$ lower deviation comparing with the GOSAT- $\mathrm{XCH}_{4}$ data within $400 \mathrm{~km}$ distance from the station. Our $\mathrm{XCH}_{4}$ data are the averaged values for the local mean solar time of 10-14 h, which show a decreasing tendency from the beginning of October to the end of November by $90 \mathrm{ppb}$ and have one 


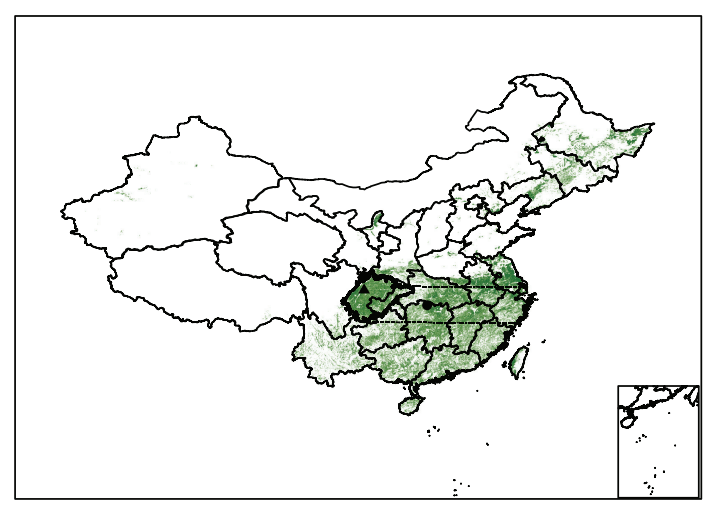

Sichuan Basin

Eastern latitude zone

Paddy fields

$$
\begin{aligned}
& \text { - Yanting } \\
& \text { - Yueyang }
\end{aligned}
$$

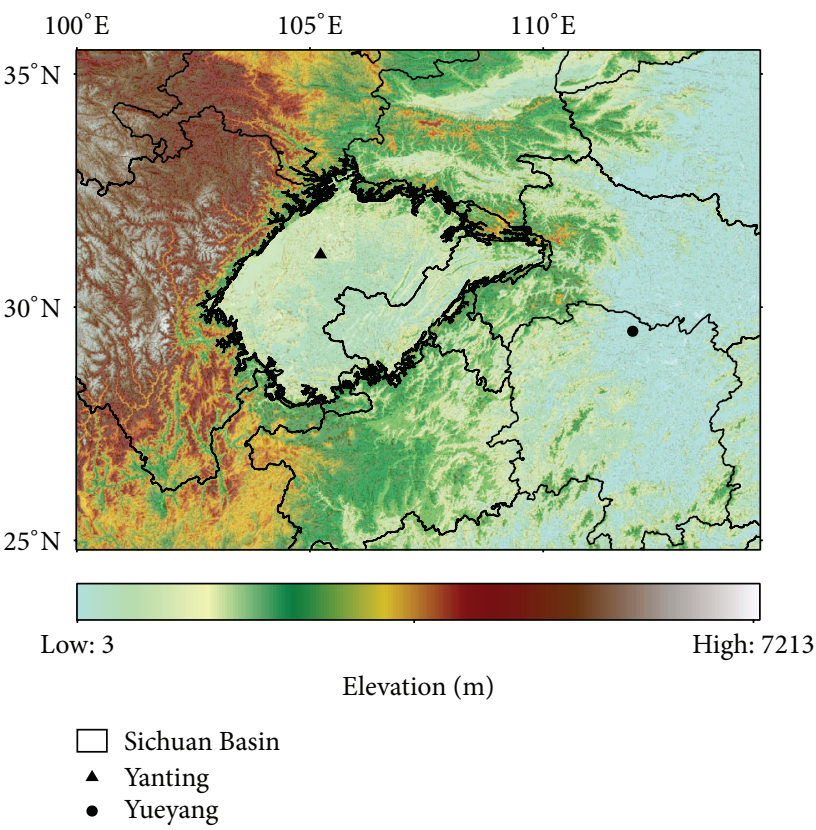

(a) Study region and paddy fields

Figure 1: (a) Paddy fields distribution in China, the Sichuan Basin (black line polygon), and the comparative study regions (within two horizontal lines) at the same latitude zone to the east of the basin, and (b) the terrain elevation of the Sichuan Basin. Also showed in (a) and (b) are the locations of Yanting (solid triangle) and Yueyang (solid circle).

standard deviation of $70 \mathrm{ppb}$. More detailed analysis is still in process.

(2) Meteorological Data. To study the relationship between air temperature and satellite-observed $\mathrm{XCH}_{4}$ concentration, monthly mean temperature data in Sichuan Basin and the paddy area in the same latitude zone are collected from the China Meteorological Data Sharing System (http://data.cma .gov.cn/) [23], which are based on the basic-reference surface weather observation station and automatic stations in China. We obtain the temperature data from the 19 stations in Sichuan Basin and 33 stations in the paddy areas in the same latitude zone from January 2010 to December 2013 and calculate the regional monthly mean temperature of the two areas for the following analysis.

(3) Emission Dataset. $\mathrm{CH}_{4}$ emissions from human activities and natural processes correspond to anthropogenic sources and natural sources, respectively, in which anthropogenic emissions account for about 60\% [24]. The anthropogenic emissions are mainly from rice cultivation, ruminants, waste disposal, biomass burning, and energy industries. The used dataset of $\mathrm{CH}_{4}$ emissions is from the Emissions Database for Global Atmospheric Research (EDGAR) v4.2 data [25] for the year 2010 on spatial grid of $0.1^{\circ} \times 0.1^{\circ}$. EDGAR is a joint project of the European Commission JRC Joint Research Centre and the Netherlands Environmental Assessment Agency, and the data are mainly from point source emissions and global energy statistics database of the International Energy Agency (IEA). The EDGAR $\mathrm{CH}_{4}$ emission data include emissions from agricultural soils, gases, industrial process, and animal enteric fermentation [26]. Figure 2 shows the spatial distribution of $\mathrm{CH}_{4}$ emissions in China for the year 2010. The area of high emission sources around the Sichuan Basin is mainly located to the east and northeast, followed by the south, whereas the emissions to the west and north are almost negligible.

2.3. Trajectory Simulation Analysis. In order to study the influence of nonlocal sources and atmospheric transport on $\mathrm{CH}_{4}$ concentration, Hybrid Single-Particle Lagrangian Integrated Trajectory (HYSPLIT) model is used to simulate the atmospheric transport by successively setting Yanting and Yueyang as center point under the weather conditions of the year 2013. The HYSPLIT model is a complete system, developed jointly by NOAA and Australia's Bureau of Meteorology, for computing simple air parcel trajectories to complex dispersion and deposition simulations, allowing for a variety of meteorological elements in the input file, varying physical processes, and different types of emission sources. Past studies showed that 3-5-day trajectory simulation is an appropriate simulation period to study regional impact [27, 28]. Therefore, three-day (72 hours) period is chosen in this study to implement the trajectory simulation using HYSPLIT. The simulations were started from the UTC time 00:00, 06:00, 12:00, and 18:00, respectively, with simulated height of 500 meters above the ground. The simulated trajectories are aggregated using $0.5^{\circ} \times 0.5^{\circ}$ grids to calculate the number of trajectory lines and the corresponding orientations within each grid under certain atmospheric conditions. $\mathrm{CH}_{4}$ sources 


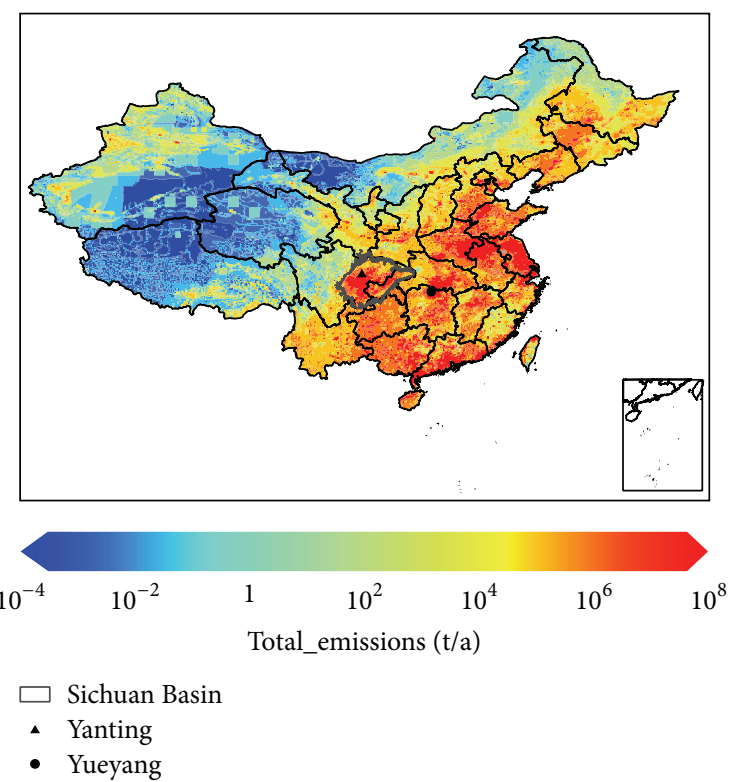

Figure 2: Amount of $\mathrm{CH}_{4}$ emissions in China region in 2010 from EGDAR 4.2 data (colorbar of the emission value are shown by taking their base 10 logarithms).

and sinks can then be further analyzed by combining the simulation data and the distribution of $\mathrm{CH}_{4}$ emissions.

\section{Results and Discussions}

3.1. Spatiotemporal Variability of $\mathrm{XCH}_{4}$. Using the GOSAT $\mathrm{XCH}_{4}$ Level 2 dataset collected from January 2010 to December 2013, we aggregated all the data into $2.5^{\circ} \times 2.5^{\circ}$ grids and calculated the averaged data within each grid to obtain the spatial distribution of $\mathrm{XCH}_{4}$ in China, as shown in Figure 3. We found that the spatial variation of $\mathrm{XCH}_{4}$ from GOSAT is generally consistent with $\mathrm{XCH}_{4}$ bottom-up calculated emission data from EDGAR as shown in Figure 2. From Figure 3, it can be seen that west China shows a much lower value than southeast region. The lowest value exists in QinghaiTibet Plateau, where little $\mathrm{CH}_{4}$ emission happens because the elevation is high (about 3000 meters on average) and there are much less human activities. However, the Sichuan Basin next to the Qinghai-Tibet Plateau presents the highest $\mathrm{XCH}_{4}$ concentration in China. This overall distribution from GOSAT data shown in Figure 3 agrees with previous studies [29].

A more detailed demonstration of the $\mathrm{XCH}_{4}$ seasonal variations is shown in Figure 4, in which the seasonal variation of all the GOSAT $\mathrm{XCH}_{4}$ data in China region with monthly mean data, the Sichuan Basin, and the rice paddy fields in the same latitude zone is compared. The $\mathrm{XCH}_{4}$ value in China land region varies from 1702 to $1917 \mathrm{ppb}$ with mean value of $1794 \mathrm{ppb}$ and also presents an annual increase and a seasonal cycle with the highest value in Autumn (July to September) and the lowest value in Winter (November to January). This temporal variation is consistent with groundbased observation result from Waliguan, one of the World

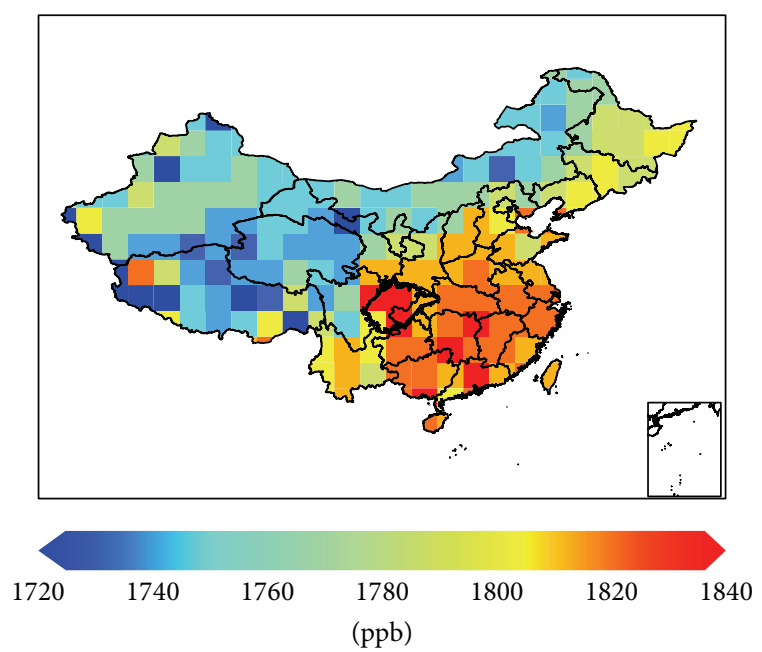

FIGURE 3: Spatial distribution of $\mathrm{XCH}_{4}$ aggregated into $2.5^{\circ} \times 2.5^{\circ}$ from GOSAT observations spanning from January 2010 to December 2013.

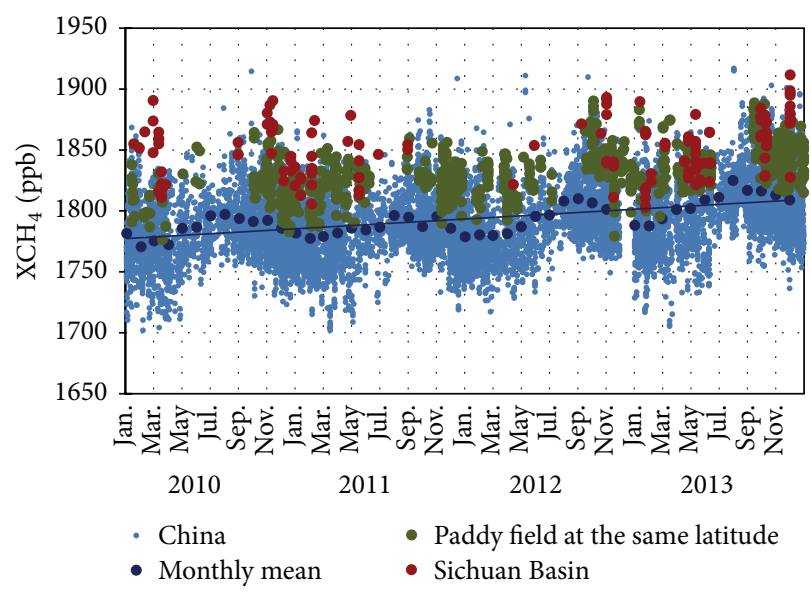

FIGURE 4: The seasonal variation of all the GOSAT $\mathrm{XCH}_{4}$ data over China land region (light blue dots), the Sichuan Basin (red dots), and the rice paddy fields (dark green dots) in the same latitude zone from January 2010 to December 2013. The dark blue dots are the monthly mean for land region and the blue line shows the corresponding trend from linear fitting.

Data Centre for Greenhouse Gases (WDCGG) stations in China [30, 31]. Moreover, $\mathrm{XCH}_{4}$ in both of the Sichuan Basin and the rice paddy field area in the same latitude zone of the basin presents general higher $\mathrm{XCH}_{4}$ value than the average value in China land region, and $\mathrm{XCH}_{4}$ value in the previous region is on average $17 \mathrm{ppb}$ higher than that in latter region. The difference of $17 \mathrm{ppb}$ is larger than the standard deviation (12.6 ppb) of the GOSAT XCH 4 data error, indicating a $\mathrm{XCH}_{4}$ difference between the two regions with high confidence.

Two main factors that contribute to the $\mathrm{XCH}_{4}$ concentration variability are the local surface $\mathrm{CH}_{4}$ emission and the large scale atmosphere dynamic transport. Among the $\mathrm{CH}_{4}$ emissions, more than $60 \%$ percent are from human activities, in which agriculture related emissions are the main 


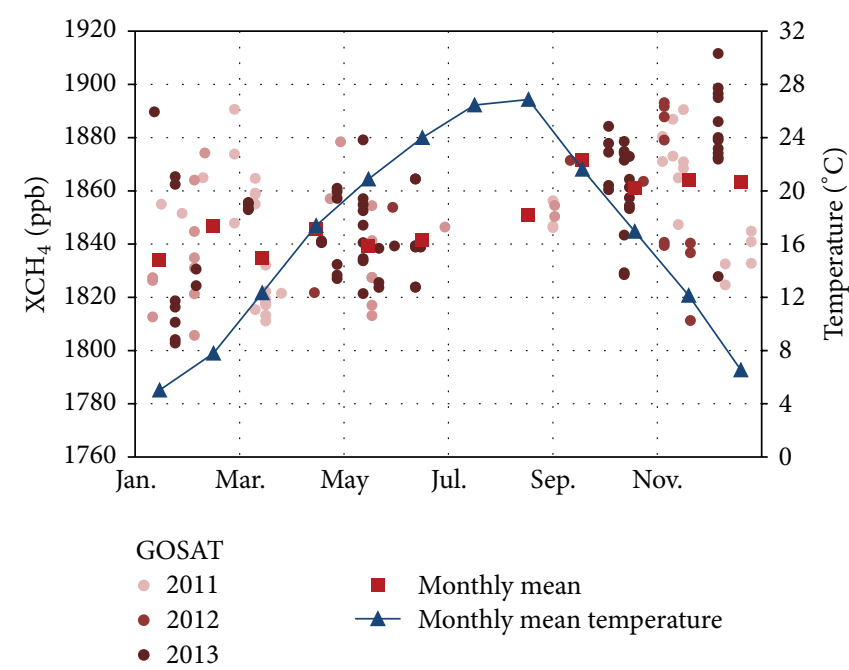

(a) Sichuan

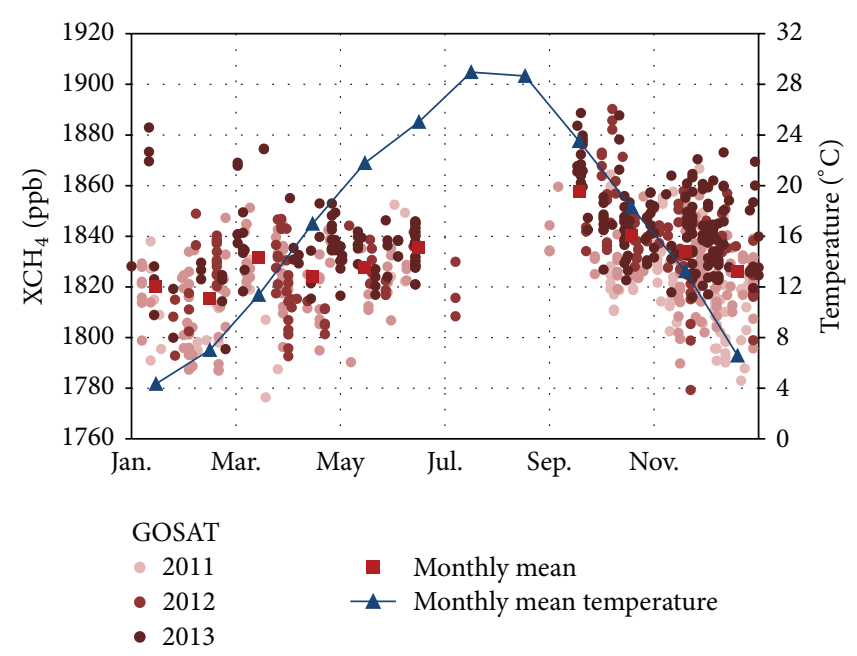

(b) Paddy field at the same latitude

FIGURE 5: Comparison of $\mathrm{XCH}_{4}$ value from GOSAT and the corresponding surface air temperature values from weather stations in (a) the Sichuan Basin and (b) the rice paddy fields in the same latitude region. The time lable of months in $x$-axis indicates the beginning of each month.

component. According to statistics from EDGAR, as shown in Figure 2, in the Sichuan Basin the proportions of $\mathrm{CH}_{4}$ emissions from agriculture related emission, fuel gas, and waste water are $44 \%, 14 \%$, and $13 \%$, respectively. On the other hand, the typical closed topography of Sichuan Basin, which results in low surface wind speed and $\mathrm{CH}_{4}$ accumulation and keeps it from outward diffusion, together with high $\mathrm{CH}_{4}$ emissions from large area of rice paddy fields in the Sichuan Basin is possibly the main reasons for the high $\mathrm{XCH}_{4}$ value in region [29]. To further investigate the high $\mathrm{XCH}_{4}$ value in this region, two factors, including the emission mechanism of rice paddy which is the main $\mathrm{CH}_{4}$ emission source and the regional atmosphere dynamic transportation, are analyzed to investigate the underlying processes leading to $\mathrm{XCH}_{4}$ variability in the Sichuan Basin.

3.1.1. Relationship between Seasonal Variation of $\mathrm{XCH}_{4}$ and Emissions from Rice Paddies. Emissions of $\mathrm{CH}_{4}$ from rice paddies become active through soil $\mathrm{CH}_{4}$ production, reoxidation, and transmission and release from plant through the aeration organizations [30]. The emission process of $\mathrm{CH}_{4}$ is influenced by many factors including weather, water management, fertilization, soil respiration, and rice growth $[30,32,33]$. As shown by previous studies, the temperature is one of the most important factors influencing the $\mathrm{CH}_{4}$ emissions from rice paddies $[34,35]$ and the $\mathrm{CH}_{4}$ emission will increase 3 times as the temperature increases by $10^{\circ} \mathrm{C}$ [36]. The Sichuan Basin paddy region mainly includes winter rice paddy, which is characterized by irrigation in March, planting in May, and rice harvesting in September. Afterwards the land keeps soil moisture and remains arable until transplanting rice in the following May $[29,33]$. This kind of paddy field is flooded during all four seasons to keep the soil in a reduced state.
Figures 5(a) and 5(b) show the relationship between the monthly averaged surface air temperature from weather stations and the $\mathrm{XCH}_{4}$ values in the Sichuan Basin and the corresponding paddy fields in the same latitude zone, respectively. From Figure 5(a), in the Sichuan basin region the averaged $\mathrm{XCH}_{4}$ value in September is generally higher than that in May, as expected according to the seasonal variation of $\mathrm{CH}_{4}$ emissions due to rice paddy cultivation with planting in May and harvest in September. However, $\mathrm{XCH}_{4}$ value during the noncultivation season, especially from November to December and January to February, is unexpectedly higher than that in September which is the harvest month in cultivation. As shown in Figure 5(b), paddy rice regions in the same latitude zone show a different feature from the Sichuan Basin. From the available monthly mean $\mathrm{XCH}_{4}$ data shown in Figure 5, we can see that both regions present an annual maximum of $\mathrm{XCH}_{4}$ concentration in September. Moreover, we found the seasonal variation of $\mathrm{XCH}_{4}$ of paddy regions in the latitude zone as shown in Figure 5(b) agrees well with the seasonal variation of surface air temperature, while the Sichuan Basin in Figure 5(a) presents a relatively higher $\mathrm{XCH}_{4}$ value during low temperature period in winter. For the period during July and August, unfortunately, almost no GOSAT $\mathrm{XCH}_{4}$ data are available during this rainy season because of the frequency clouds. As presented by Hayashida et al. [10] using the SCIAMACHY data, this period, which is right before the paddy harvest time, presents the highest $\mathrm{CH}_{4}$ concentration, corresponding to the highest surface air temperature.

It can be concluded that, in the Sichuan Basin region as in Figure 5(a), the seasonal variation of $\mathrm{XCH}_{4}$ is generally consistent with $\mathrm{CH}_{4}$ emissions from cultivation of rice paddy fields. However, higher $\mathrm{XCH}_{4}$ is unexpectedly observed during the low temperature period in winter, which will be 
further investigated in the following sections in this paper. For the rice paddy fields located in the same latitude zone in Figure 5(b), the seasonal variation of $\mathrm{XCH}_{4}$ generally agrees with $\mathrm{CH}_{4}$ emissions from cultivation of rice paddy fields and is consistent with the surface air temperature variation.

\subsubsection{Relationship between $\mathrm{XCH}_{4}$ Variation and Atmospheric} Transport. HYSPLIT model is used to simulate atmospheric transport and trajectories to investigate the influence of transport on high $\mathrm{XCH}_{4}$ concentration in January, February, November, and December in the Sichuan Basin. Based on the source of gas molecules, a simulation can be categorized into backward trajectory simulation and forward trajectory simulation. A backward track simulation can be used to analyze the impact of external sources on local circumstances, and a forward trajectory simulation can be used to examine atmospheric dynamics and transport in a specific region. In this study, we chose Yanting and Yueyang in Sichuan Basin, as shown in Figure 1, as the target regions and implemented both the forward and backward simulation every three days beginning, respectively, from the two target regions at four UTC times (00:00, 06:00, 12:00, 18:00) each day for the year 2013. There are in total 4 trajectories for each target regions each day. Figure 6 shows gridded results from the backward simulation of the Sichuan Basin for each month in 2013. Figure 7 shows the results from forward trajectory simulation by setting Yanting and Yueyang city as the target regions in the year 2013.

Using all the trajectories from HYSPLIT forward simulation, as shown in Figure 7, we calculate the number of trajectories that remains in the target regions within different time ranges, to study the atmospheric transport and diffusion of $\mathrm{CH}_{4}$ molecules from the study regions. Each trajectory line from the HYSPLIT output is a series of 73 hourly trajectory points, including the initial time ( 0 hours) and all hourly output of the 3 -day simulation ( 3 day $\times 24$ hours). For each trajectory line, the time when the line intersects with the study region boundary is obtained and then used to calculate the staying time of the molecule inside the study area. The total number of daily trajectories inside the study region is grouped into 4 different time lengths $(0,12,24$, and 48 hours) and then further grouped into monthly statistics using the following equation:

$$
\begin{aligned}
L_{m}=\sum_{j=1}^{m_{d}} \sum_{i=1}^{4} n_{i j} \begin{cases}n_{i j}=1 & \left(h_{i j} \geq H\right) \\
n_{i j}=0 & \left(h_{i j}<H\right)\end{cases} \\
\quad\left(H=0,12,24,48 ; h_{i j} \in(0,72]\right),
\end{aligned}
$$

where $L_{m}$ is the number of trajectories staying inside the study area in month $m, m_{d}$ is the number of days in the corresponding month, $i$ is the daily number of trajectories, $j$ is the $j$ th day in month $m$, and $h_{i j}$ is the time length from target point to the area boundary of the $i$ th trajectory in $j$ th day, which quantify the transport time by the molecules to be transported out of the study region. The value is from 0 to 72 hours. $H$ stands for the 4 different time lengths. We define the Sichuan Basin region (Figure $7(\mathrm{a})$ ) and the circle region centering on Yueyang with $2.5^{\circ}$ radius (Figure $7(\mathrm{~b})$ ) as two target regions. Figure 8 shows the number of $\mathrm{CH}_{4}$ molecule trajectories staying inside these two target regions after 4 different transport running times in each month for the year 2013 calculated from (1) based on the forward simulations.

From Figure 8, in the Sichuan Basin region the number of staying trajectories is generally higher than Yueyang area, especially the result after 48 hours of transport, which indicates a strong gas retention phenomenon in the Sichuan Basin. For January, February, November, and December in the basin region, the number of staying trajectories inside this area is obviously larger than other months, even after 48 hours of transport. However, the number of staying trajectories in Yueyang region is smaller in these months. Comparing with seasonal variation of $\mathrm{XCH}_{4}$ in Figure 5, we found the seasonal variation of the number of staying trajectories inside the study region agrees well with the seasonal variation of $\mathrm{XCH}_{4}$. Moreover, from Figure 7 we found in the Sichuan Basin area the air parcel trajectories are aggregating in a volute shape, indicating a weak outward diffusion of the $\mathrm{CH}_{4}$ molecules. However, the overall atmosphere transport in Yueyang as observed from the trajectories is distributed obviously along the northeast and southwest direction, which is very different from the Sichuan Basin possibly mainly due to their different topographies.

Compared with the backward simulation results in Figure 6, the Sichuan Basin is weakly influenced by emissions from a small part of the eastern China source region in February and from northeastern part in November and is consistently and greatly influenced from north regions all the year, where, however, almost no $\mathrm{CH}_{4}$ emission sources exist according to EDGAR emission data shown in Figure 2. Therefore, we conclude that, in January, February, November, and December, the $\mathrm{CH}_{4}$ in Sichuan Basin is partly affected by the $\mathrm{CH}_{4}$ emissions from the northeast and north regions, where the emissions are small, indicating the high $\mathrm{XCH}_{4}$ values during these four months are not results of strong influence by external emission sources.

Regarding $\mathrm{CH}_{4}$ emission from sources other than rice paddies, which might be impacting the spring/winter high in Sichuan Basin, we examined the GISS bottom-up emission inventory data [37] as shown in Figure 8 (6-2) in Hayashida et al. [10]. We found that during the cultivation season almost all the $\mathrm{CH}_{4}$ emission is from rice cultivation, while during the winter noncultivation season the rice emission is close to zero and the emissions from other sources are also very small that the GOSAT-observed high $\mathrm{XCH}_{4}$ value during spring/winter is not likely from these sources.

From both the spatial and temporal variation of $\mathrm{XCH}_{4}$ from GOSAT data as described and discussed above, it can be concluded that the typical closed topography of Sichuan Basin, which leads to $\mathrm{CH}_{4}$ accumulation and keeps it from diffusion, is one important reason for the high $\mathrm{XCH}_{4}$ value observed in this region.

As the main sink of atmospheric $\mathrm{CH}_{4}$, the reaction of $\mathrm{CH}_{4}$ with hydroxyl radicals $(\mathrm{OH})$ removes almost $90 \%$ of $\mathrm{CH}_{4}$ [38]. Because of a stronger chemical loss that happened in summer, the $\mathrm{CH}_{4}$ concentrations are generally lowest in summer and highest in winter, as reported by [39] using 

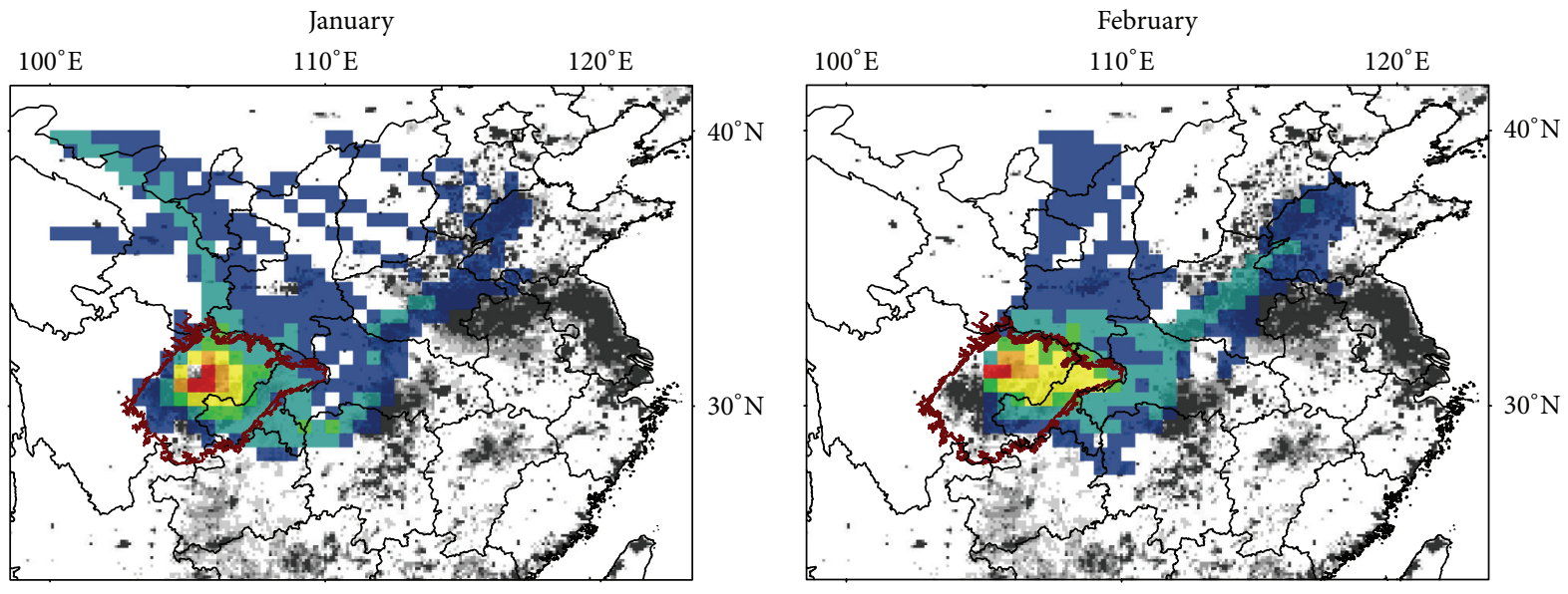

\begin{tabular}{l|l|l} 
Number of lines & & \\
$1-4$ & $12-22$ & $41-74$ \\
$5-11$ & $23-40$ & $75-143$
\end{tabular}
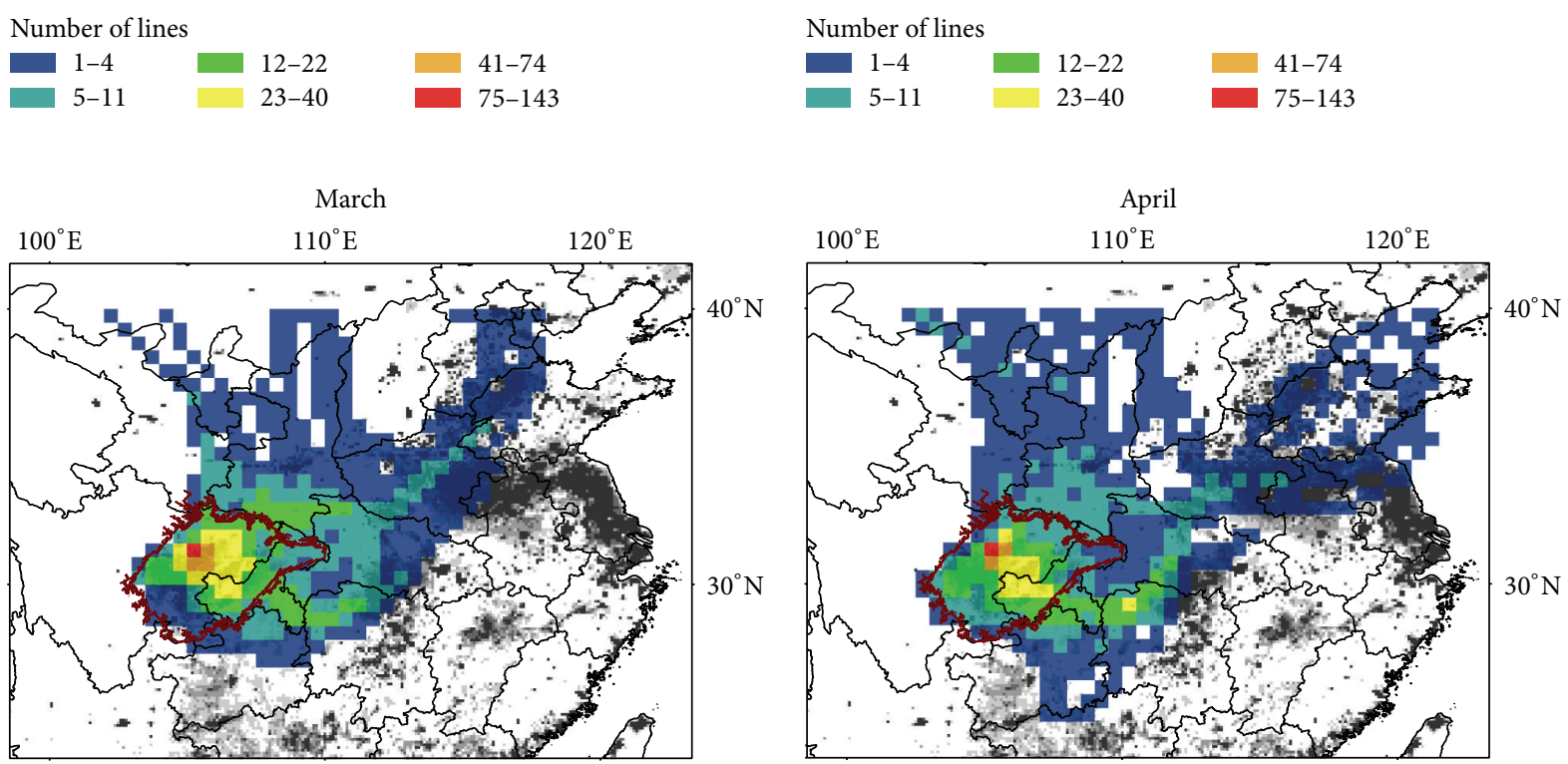

Number of lines

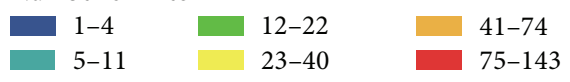

Number of lines
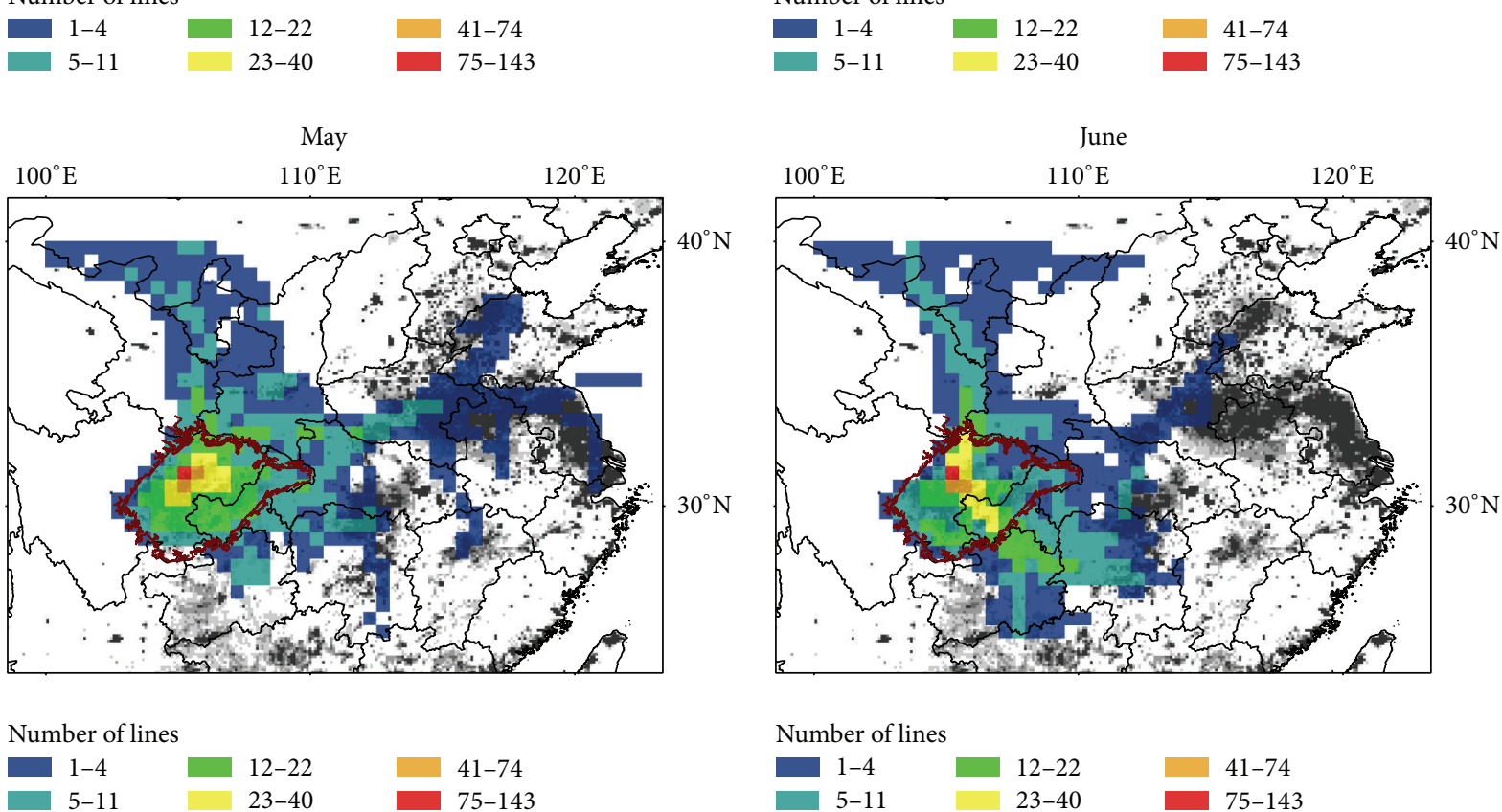

Figure 6: Continued. 

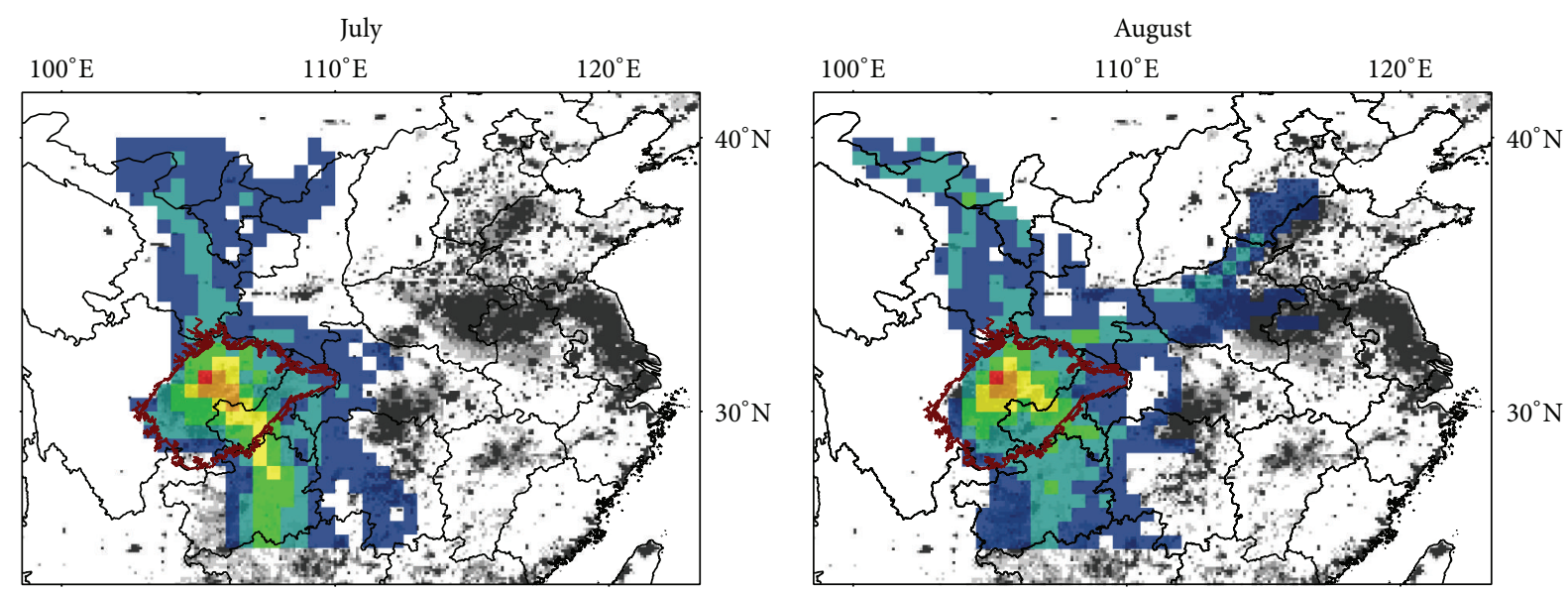

Number of lines

$\begin{array}{lll}1-4 & 12-22 & 41-74 \\ 5-11 & 23-40 & 75-143\end{array}$

$\begin{array}{lll}\text { Number of lines } & & \\ 1-4 & 12-22 & 41-74 \\ 5-11 & 23-40 & 75-143\end{array}$
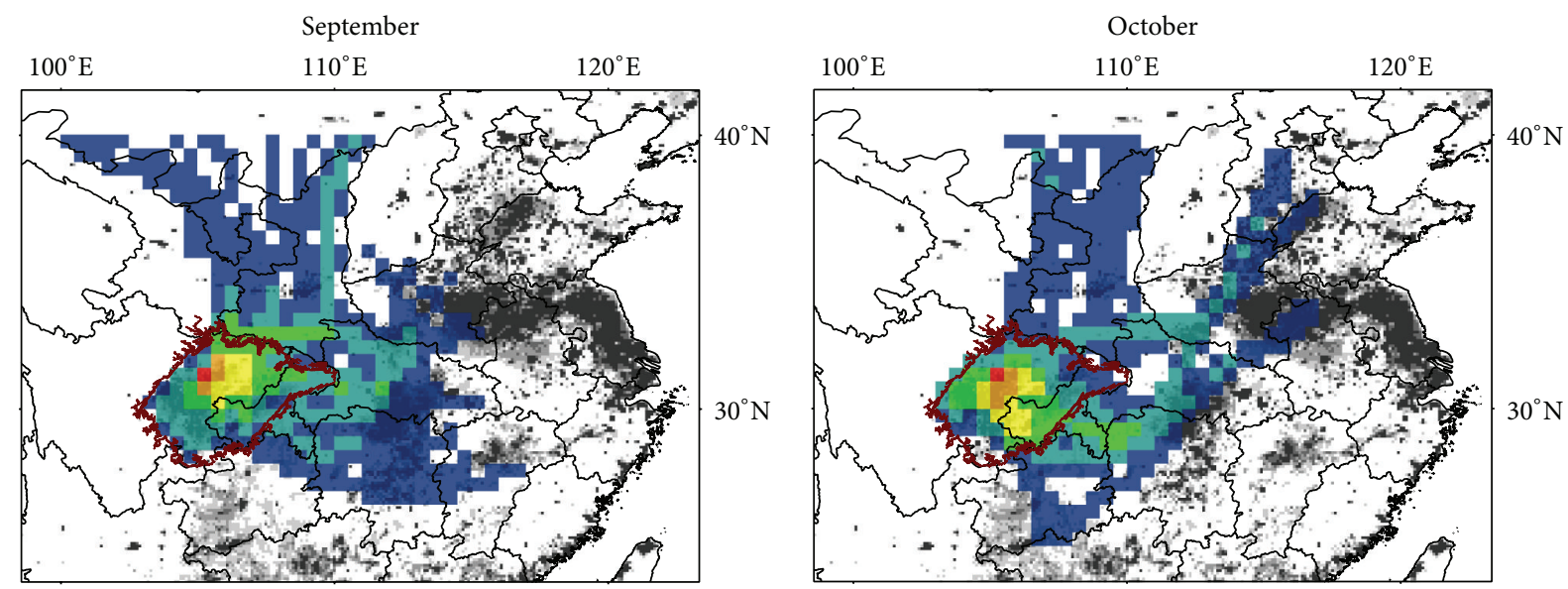

Number of lines

\begin{tabular}{l|l|l}
$1-4$ & $12-22$ & $41-74$ \\
$5-11$ & $23-40$ & $75-143$
\end{tabular}

Number of lines
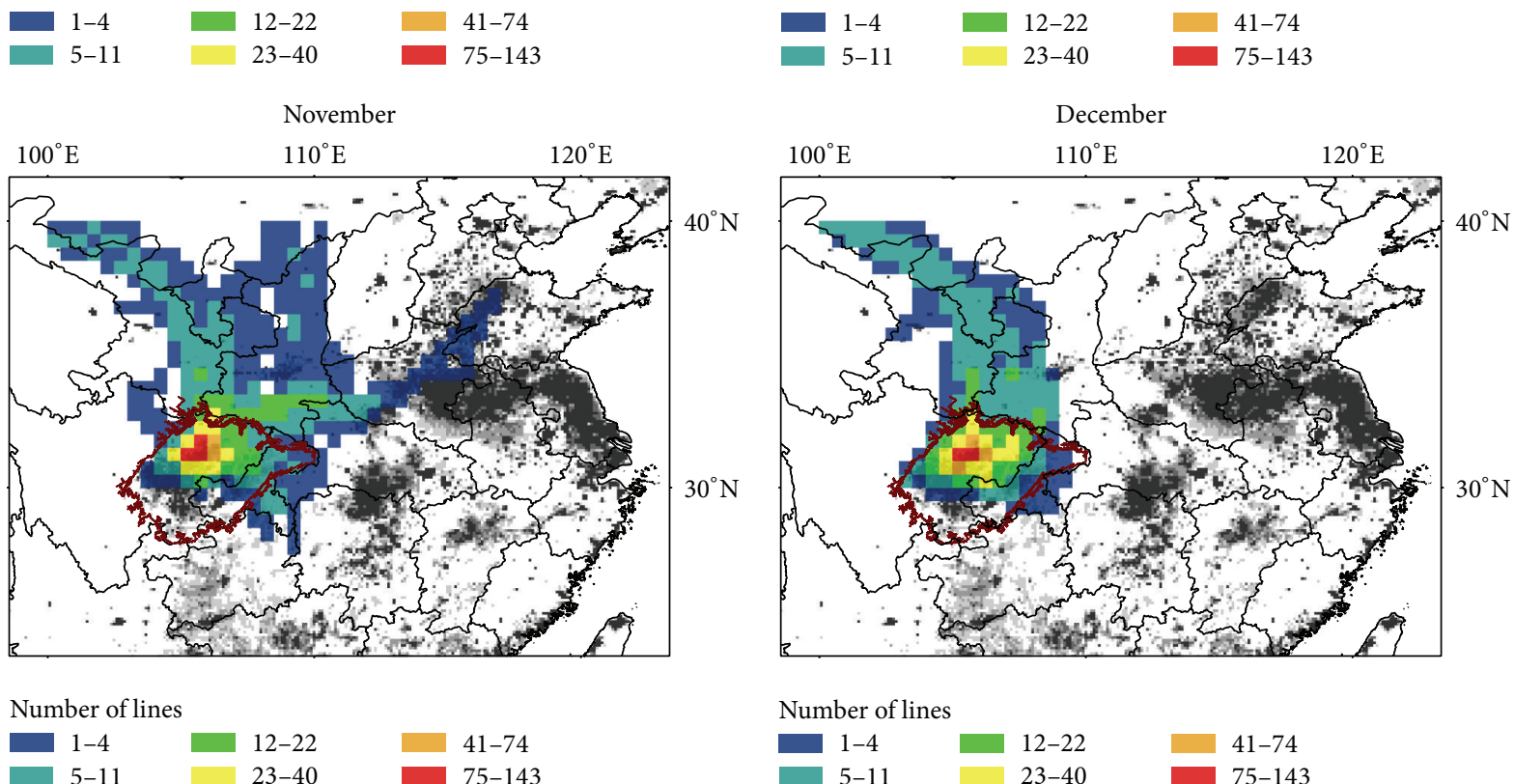

Figure 6: The density of the backward simulated trajectories, which are gridded into 0.5 by 0.5 degree grids, from Yanting in the Sichuan Basin for each month in 2013. 


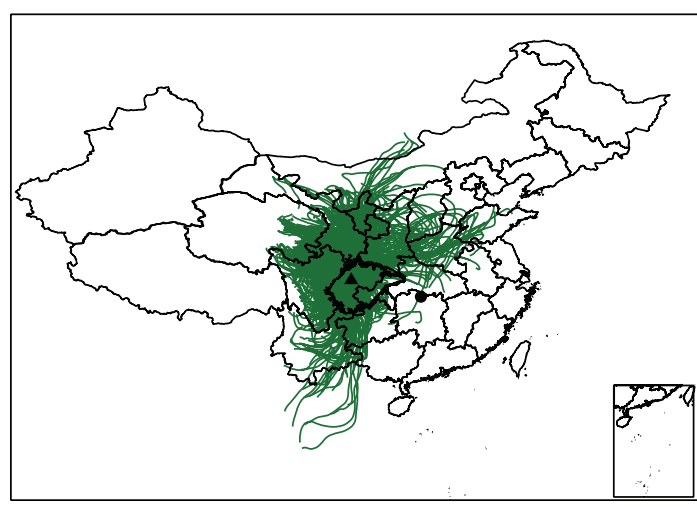

- Yanting

- Yueyang
Sichuan Basin

Yanting forward

(a) Yanting

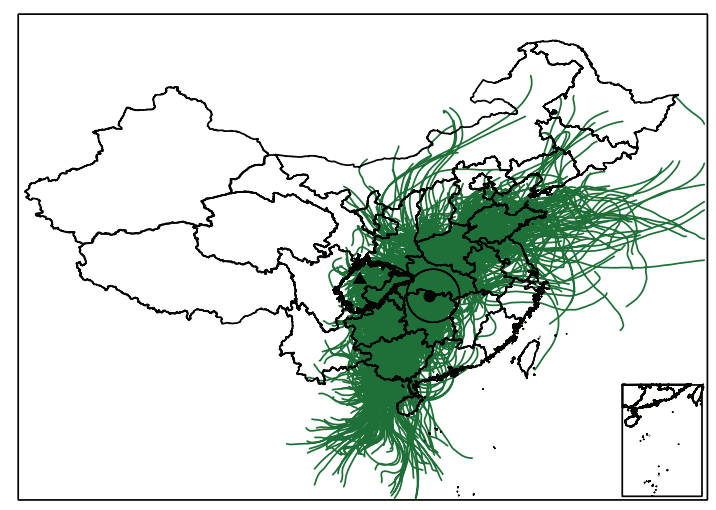

$\begin{array}{lll}\text { - Yanting } & \bigcirc & \text { Yueyang area } \\ \text { Yueyang } & \text { Yueyang forward } \\ \square & \text { Sichuan Basin } & \end{array}$

(b) Yueyang

FIGURE 7: The spatial distribution of forward trajectory simulation from (a) Yanting (solid triangle) in Sichuan Basin and (b) Yueyang area (solid circle).

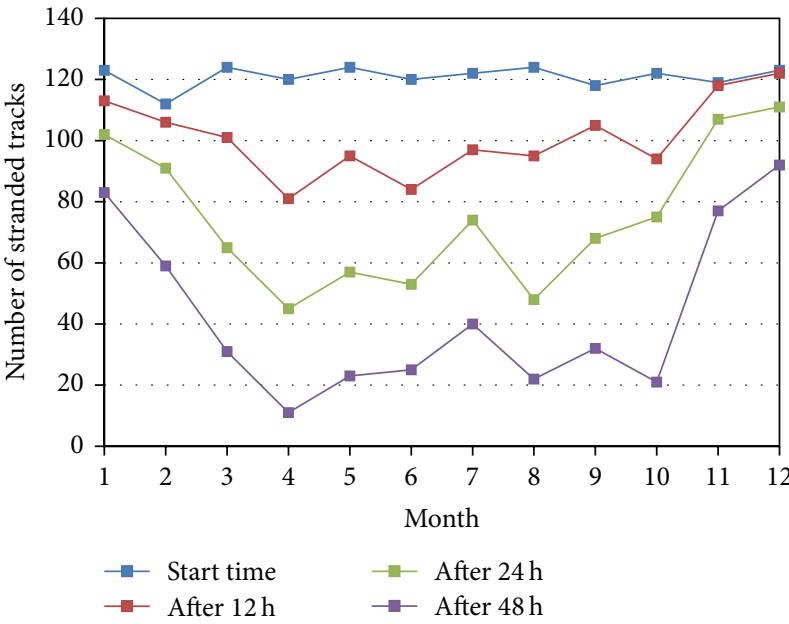

(a)

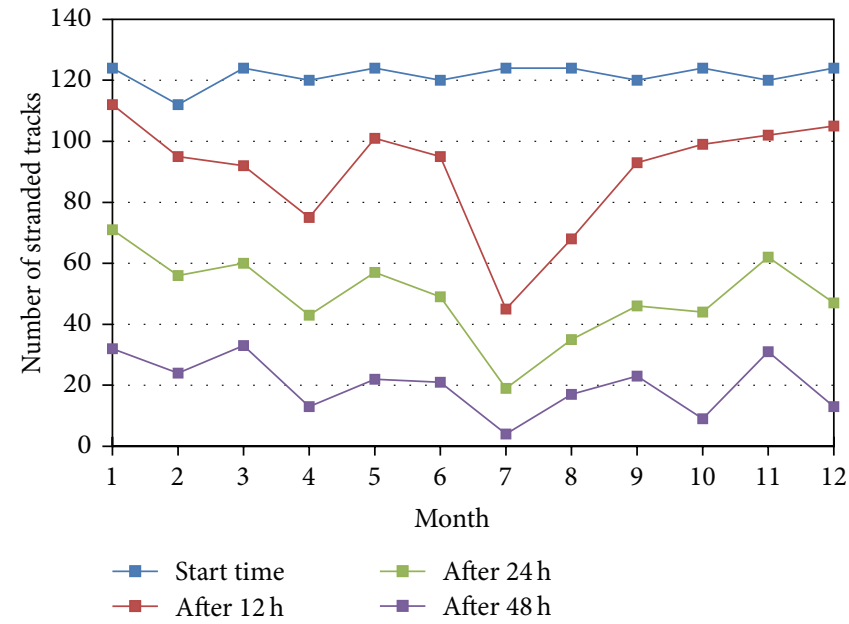

(b)

FiguRE 8: The number of trajectories that still stay inside the study area of (a) the Sichuan Basin and (b) the circle region centering on Yueyang with $2.5^{\circ}$ radius after 4 different transport times $(0,12,24$, and 48 hours).

the background observations from the monitoring network data. However, GOSAT $\mathrm{XCH}_{4}$ data in this study shows a different seasonal variation in Sichuan Basin characterized by higher concentration during summer and autumn (rice cultivation season) and lower concentration during winter and spring (noncultivation season), which are consistent with Hayashida et al. [10] using the SCIAMACHY $\mathrm{XCH}_{4}$ data. Unfortunately, few $\mathrm{XCH}_{4}$ retrievals from GOSAT during summer are available for further investigation.

\section{Conclusions}

In this study, GOSAT- $\mathrm{XCH}_{4}$ data from January 2010 to December 2013 are used to study the spatiotemporal variation of $\mathrm{XCH}_{4}$ in China, especially for Sichuan Basin where it presents consistent higher $\mathrm{XCH}_{4}$ values than other parts of China. We further investigate the driving factors, including the $\mathrm{CH}_{4}$ emissions and regional atmosphere dynamic transport, to study the variations of $\mathrm{CH}_{4}$ concentration in the basin and evaluate the potential role of satellite-observed $\mathrm{XCH}_{4}$ data in analyzing the regional variation of $\mathrm{CH}_{4}$.

Our results show that the spatial distribution of GOSAT$\mathrm{XCH}_{4}$ is generally consistent with that of $\mathrm{CH}_{4}$ emission, and abnormal high $\mathrm{XCH}_{4}$ values can be seen in the Sichuan Basin, which is consistent with previous results from SCIAMACHY $[10,12]$. The seasonal variation of $\mathrm{XCH}_{4}$ is highly related to the $\mathrm{CH}_{4}$ emissions from rice paddy fields during rice growing period from April to October and presents a difference feature from background $\mathrm{CH}_{4}$ variation related to stronger $\mathrm{CH}_{4}$ loss in summer due to chemical reaction. During the rice 
harvesting season of August to September, $\mathrm{XCH}_{4}$ data are higher than that in early stage of rice growing in April. However, the abnormal high $\mathrm{XCH}_{4}$ data are shown in the winter when the $\mathrm{CH}_{4}$ emissions from rice paddy fields are weak and the surface air temperature is low. By implementing the trajectory simulation using HYSPLIT in the basin, we found the typical closed topography of Sichuan Basin, which may lead to $\mathrm{CH}_{4}$ accumulation and keep it from diffusion, is one possible reason for the extreme high $\mathrm{XCH}_{4}$ value in winter. The influence of $\mathrm{CH}_{4}$ emissions from sources other than rice paddies is also discussed and bottom-up emission inventory data show that they are not likely big causes of the observed winter high $\mathrm{XCH}_{4}$ value in Sichuan Basin. It can be indicated that the regional variations of $\mathrm{XCH}_{4}$ observed by GOSAT in Sichuan Basin are determined by not only the $\mathrm{CH}_{4}$ emissions from ground sources but also very likely the regional topography and the related regional air transport.

Our result from studying the $\mathrm{CH}_{4}$ variations in Sichuan Basin, especially the abnormal higher value during winter, and their driving factors demonstrate a certain potential of using GOSAT- $\mathrm{XCH}_{4}$ for investigating the regional $\mathrm{CH}_{4}$ changes. This study presents preliminary results of $\mathrm{CH}_{4}$ in China, and a further investigation of the $\mathrm{CH}_{4}$ in the basin is still necessary as more satellite observations of $\mathrm{CH}_{4}$ with improving accuracy are available in the coming future to further study the $\mathrm{CH}_{4}$ variations and regional emissions [40].

\section{Conflict of Interests}

The authors declare that there is no conflict of interests regarding the publication of this paper.

\section{Acknowledgments}

This work was supported by the Strategic Priority Research Program-Climate Change (XDA05040401) and the National High Technology Research and Development Program of China (2012AA12A301). The authors are grateful for the valuable and excellent comments from the reviewer and editor and acknowledge the data products provided by NIES GOSAT Project (https://data.gosat.nies.go.jp/gateway/gateway/MenuPage/open.do) and China Meteorological Data Sharing System (http://data.cma.gov.cn/) and EDGAR (http://edgar.jrc.ec.europa.eu/). Masahiro Kawasaki, Masafumi Ohashi, and Yutaka Matsumi acknowledge the financial supports from JSPS, JST, and GRENE-ei of the Ministry of Education, Science, Culture and Sports of Japan.

\section{References}

[1] K. B. Hogan, A. M. Thompson, and J. S. Hoffman, "Methane on the greenhouse agenda," Nature, vol. 354, no. 6350, pp. 181-182, 1991.

[2] Q. He, T. Yu, X. F. Gu, T. H. Cheng, Y. Zhang, and D. H. Xie, "Global atmospheric methane variation and temporal-saptial distribution analysis based on ground-based and satellite data," Remote Sensing Informations, vol. 27, no. 4, p. 35, 2012.

[3] R. X. Shen, X. J. Shangguan, M. Wang et al., "Methane emission from rice fields in Guangzhou region and the spatial variation of methane emission in China," Advances in Earth Science, vol. 10, no. 4, pp. 387-392, 1995.

[4] L. X. Zhou, J. Tang, Y. P. Wen et al., "Characteristics of atmospheric methane concentration variation at Mt. Waliguan," Quarterly Journal of Applied Meteorology, vol. 9, no. 4, pp. 385391, 1998.

[5] WMO, "Strategy for the Implementation of the Global Atmosphere Watch Programme (2001-2007), a contribution to the implementation of the WMO longterm plan," GAW Report 142, 2001.

[6] S. Kirschke, P. Bousquet, P. Ciais et al., "Three decades of global methane sources and sinks," Nature Geoscience, vol. 6, no. 10, pp. 813-823, 2013.

[7] F. Deng, D. B. A. Jones, D. K. Henze et al., "Inferring regional sources and sinks of atmospheric $\mathrm{CO}_{2}$ from GOSAT $\mathrm{XCO}_{2}$ data," Atmospheric Chemistry and Physics, vol. 14, no. 7, pp. 3703-3727, 2014.

[8] X. Xiong, C. Barnet, E. Maddy et al., "Characterization and validation of methane products from the Atmospheric Infrared Sounder (AIRS)," Journal of Geophysical Research G: Biogeosciences, vol. 113, no. 3, Article ID G00A01, 2008.

[9] C. Frankenberg, J. F. Meirink, P. Bergamaschi et al., "Satellite chartography of atmospheric methane from SCIAMACHY on board ENVISAT: analysis of the years 2003 and 2004," Journal of Geophysical Research D: Atmospheres, vol. 111, no. 7, Article ID D07303, 2006.

[10] S. Hayashida, A. Ono, S. Yoshizaki, C. Frankenberg, W. Takeuchi, and X. Yan, "Methane concentrations over Monsoon Asia as observed by SCIAMACHY: signals of methane emission from rice cultivation," Remote Sensing of Environment, vol. 139, pp. 246-256, 2013.

[11] T. Yokota, Y. Yoshida, N. Eguchi et al., "Global concentrations of $\mathrm{CO}_{2}$ and $\mathrm{CH}_{4}$ retrieved from GOSAT: first preliminary results," SOLA, vol. 5, pp. 160-163, 2009.

[12] X. Xiong, S. Houweling, J. Wei, E. Maddy, F. Sun, and C. Barnet, "Methane plume over south Asia during the monsoon season: satellite observation and model simulation," Atmospheric Chemistry and Physics, vol. 9, no. 3, pp. 783-794, 2009.

[13] X. Y. Zhang, H. Jiang, Y. Q. Wang et al., "Spatial variations of atmospheric methane concentrations in China," International Journal of Remote Sensing, vol. 32, no. 3, pp. 833-847, 2011.

[14] T. Hamazaki, A. Kuze, and K. Kondo, "Sensor system for greenhouse gas observing satellite (GOSAT)," in Infrared Spaceborne Remote Sensing XII, vol. 5543 of Proceedings of SPIE, International Society for Optics and Photonics, Denver, Colo, USA, November 2004.

[15] Z. Zeng, L. Lei, L. Guo, L. Zhang, and B. Zhang, "Incorporating temporal variability to improve geostatistical analysis of satellite-observed $\mathrm{CO}_{2}$ in China," Chinese Science Bulletin, vol. 58, no. 16, pp. 1948-1954, 2013.

[16] L. Lei, X. Guan, Z. Zeng, B. Zhang, F. Ru, and R. Bu, "A comparison of atmospheric $\mathrm{CO}_{2}$ concentration GOSAT-based observations and model simulations," Science China Earth Sciences, vol. 57, no. 6, pp. 1393-1402, 2014.

[17] Z. Zeng, L. Lei, S. Hou, F. Ru, X. Guan, and B. Zhang, "A regional gap-filling method based on spatiotemporal variogram model of $\mathrm{CO}_{2}$ columns," IEEE Transactions on Geoscience and Remote Sensing, vol. 52, no. 6, pp. 3594-3603, 2014.

[18] J. X. Xia, L. J. Deng, and S. R. Zhang, "Effects of environmental factors on the Sichuan Basin rice quality," in Proceedings of the China to Soil Society 10th National Congress and the 5th 
Member Representative Cross-Strait Academic Exchanges and Fertilizer Symposium for Agricultural and Environmental Soil Science Topics Articles, 2004.

[19] X. C. Qin, L. P. Lei, M. Kawasaki et al., "Retrieval and analysis of atmospheric $\mathrm{XCO}_{2}$ using ground-based spectral observation," Spectroscopy and Spectral Analysis, vol. 34, no. 7, pp. 1729-1735, 2014.

[20] M. Kawasaki, H. Yoshioka, N. B. Jones et al., "Usability of optical spectrum analyzer in measuring atmospheric $\mathrm{CO}_{2}$ and $\mathrm{CH}_{4}$ column densities: inspection with FTS and aircraft profiles in situ," Atmospheric Measurement Techniques, vol. 5, no. 11, pp. 2593-2600, 2012.

[21] https://data.gosat.nies.go.jp/gateway/gateway/MenuPage/open .do.

[22] Y. Yoshida, N. Kikuchi, I. Morino et al., "Improvement of the retrieval algorithm for GOSAT SWIR $\mathrm{XCO}_{2}$ and $\mathrm{XCH} 4$ and their validation using TCCON data," Atmospheric Measurement Techniques, vol. 6, no. 6, pp. 1533-1547, 2013.

[23] http://data.cma.gov.cn/.

[24] World Meteorological Organization (WMO), WMO Greenhouse Gas Bulletin, No. 10, 2014.

[25] http://edgar.jrc.ec.europa.eu/.

[26] Q. Yue, G.-J. Zhang, and Z. Wang, "Preliminary estimation of methane emission and its distribution in China," Geographical Research, vol. 31, no. 9, pp. 1559-1570, 2012.

[27] A. Stohl, "Trajectory statistics-a new method to establish source-receptor relationships of air pollutants and its application to the transport of particulate sulfate in Europe," Atmospheric Environment, vol. 30, no. 4, pp. 579-587, 1996.

[28] D. D. Rousseau, D. Duzer, J. L. Etienne et al., "Pollen record of rapidly changing air trajectories to the North Pole," Journal of Geophysical Research, vol. 109, no. 6, 2004.

[29] G. J. Zhang, Temporal and Spatial Distribution of Column Vertical Density and Emission of Methane in China, East China Normal University, 2011.

[30] C. F. Wei, M. Gao, Q. Huang et al., "Effects of tillage-cropping systems on methane emission from year-round flooded paddy field in Southwest China," Acta Pedologica Sinica, vol. 37, no. 2, pp. 157-165, 2000.

[31] F. Zhang, L. Zhou, and L. Xu, "Temporal variation of atmospheric $\mathrm{CH}_{4}$ and the potential source regions at Waliguan, China," Science China Earth Sciences, vol. 56, no. 5, pp. 727-736, 2013.

[32] D. Z. Chen, M.-X. Wang, X.-J. Shangguan, and J. Huang, "Methane emission from rice fields in the south-east China," Advances in Earth Science, vol. 8, no. 5, pp. 47-54, 1993.

[33] Y. Y. Wang, W. W. Chen, Z. C. Zhao, and J.-X. Gu, "Characteristics and emission from cold paddy field in the Sanjiang Plain," Transactions of the Chinese Society of Agricultural Engineering, vol. 24, no. 10, pp. 170-176, 2008.

[34] X. J. Shangguan, M. X. Wang, and R. X. Shen, "Regularity of methane emission from rice paddy fields," Advance in Earth Science, vol. 8, no. 5, p. 23, 1993.

[35] X. K. Yu, N. Li, C. Y. Li, B. Shao, W. D. Wang, and X. L. $\mathrm{Xie}$, "Effect of temperature on methane emissions from rice paddies," Advances in Earth Science, vol. 9, no. 5, pp. 54-56, 1994.

[36] W.-D. Wang, X.-L. Xie, X.-J. Shangguan, D.-Z. Chen, and M.-X. Wang, "Laws of methane production in paddy soil in red earth hilly area of South China," Rural Eco-Environment, vol. 11, no. 3 , pp. 11-14, 1995.
[37] E. Matthews, I. Fung, and J. Lerner, "Methane emission from rice cultivation: geographic and seasonal distribution of cultivated areas and emissions," Global Biogeochemical Cycles, vol. 5, no. 1, pp. 3-24, 1991.

[38] Intergovernmental Panel on Climate Change (IPCC), Climate Change 2001: The Scientific Basis, Cambridge University Press, New York, NY, USA, 2001.

[39] World Meteorological Organization, WDCGG Data Report no. 36, 2012.

[40] R. Parker, H. Boesch, and A. Cogan, "Methane observations from the Greenhouse Gases Observing SATellite: comparison to ground-based TCCON data and model calculations," Geophysical Research Letters, vol. 38, no. 15, Article ID L15807, 2011. 

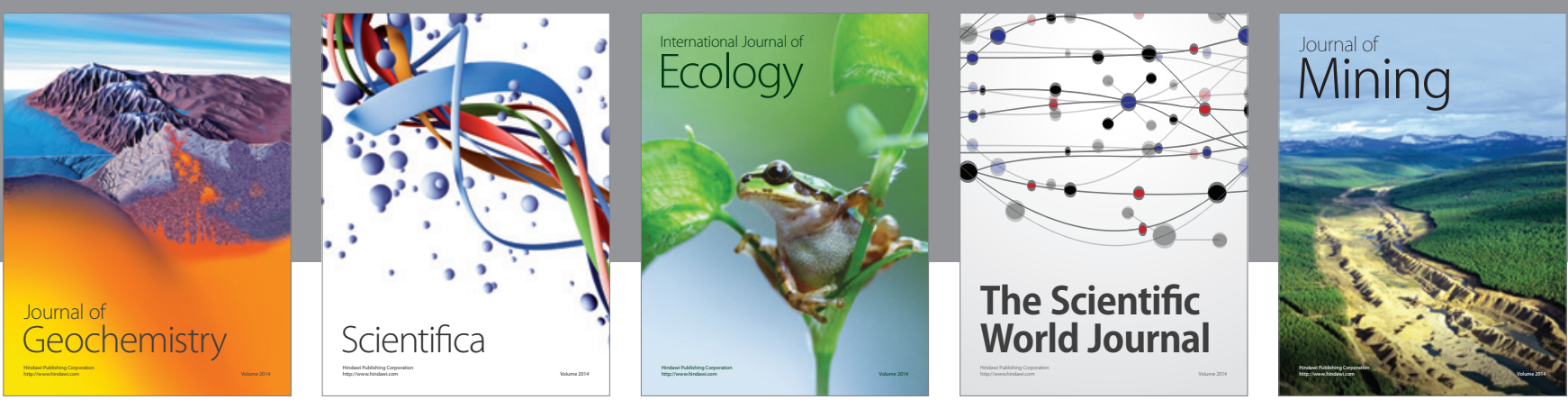

The Scientific World Journal
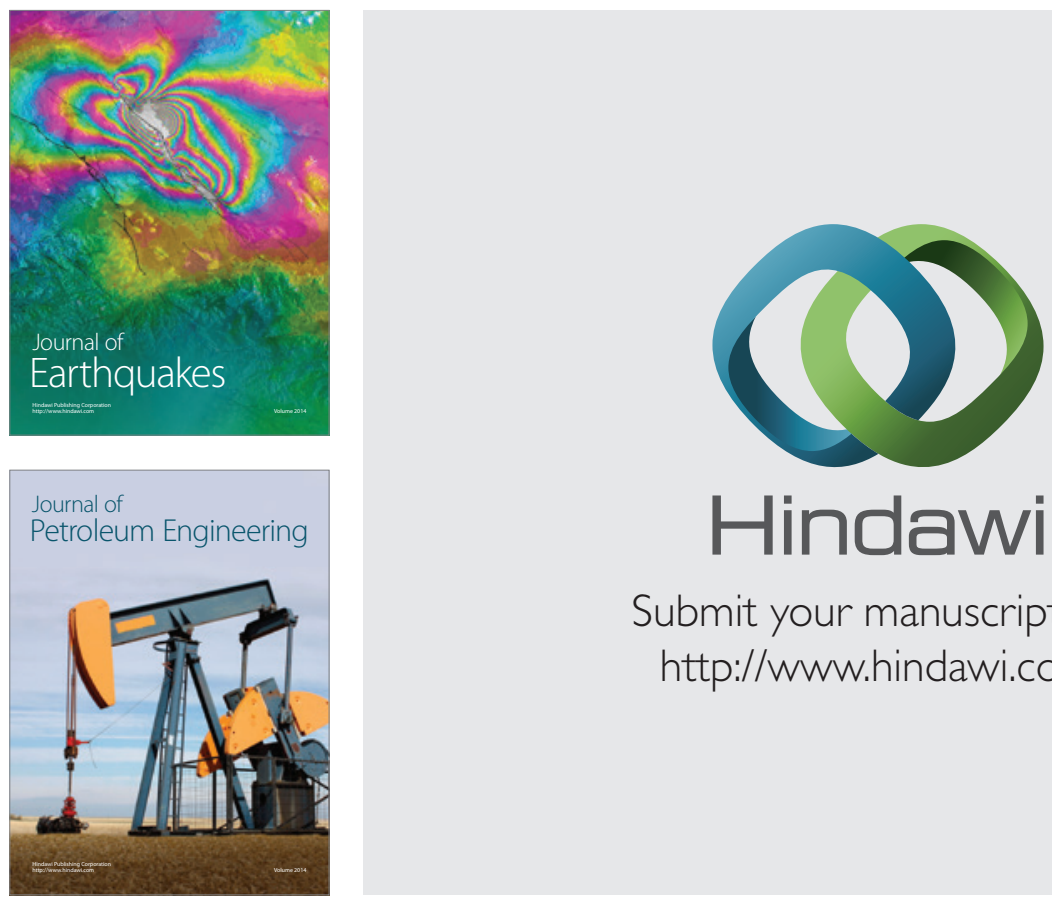

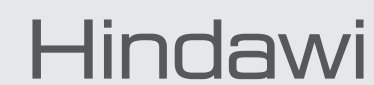

Submit your manuscripts at

http://www.hindawi.com
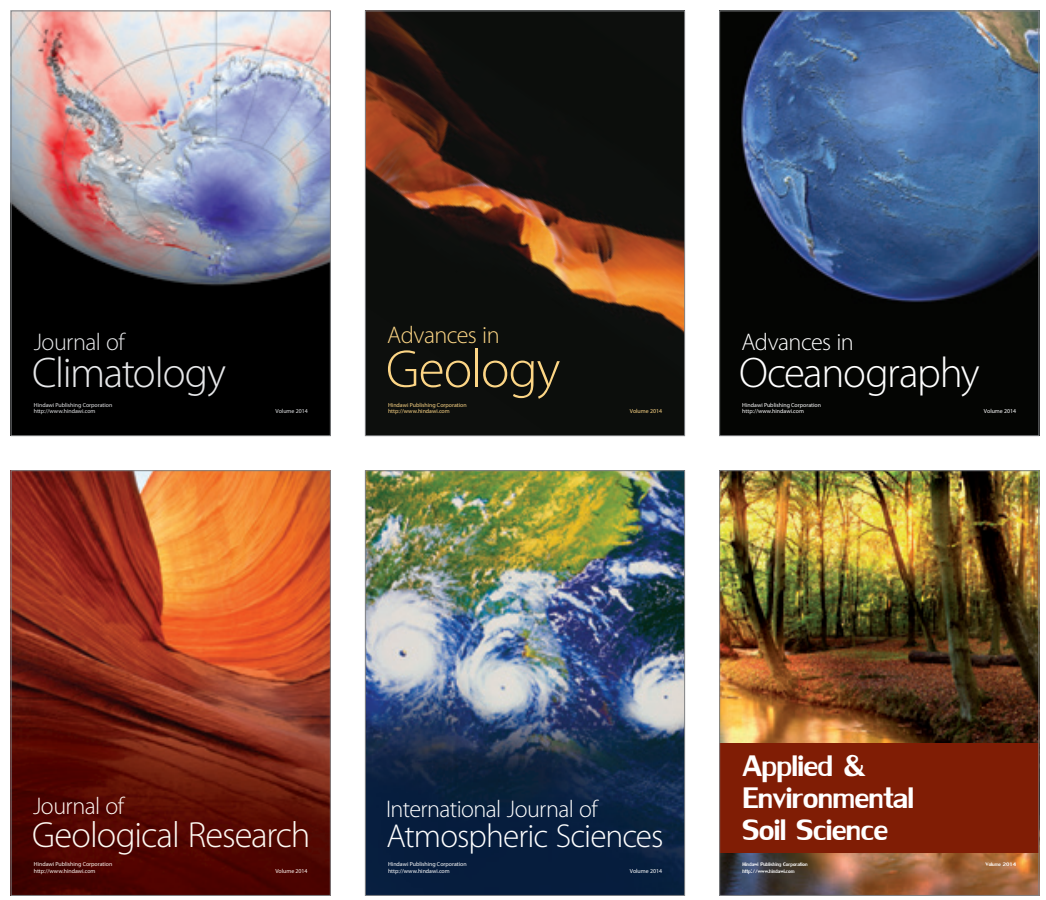
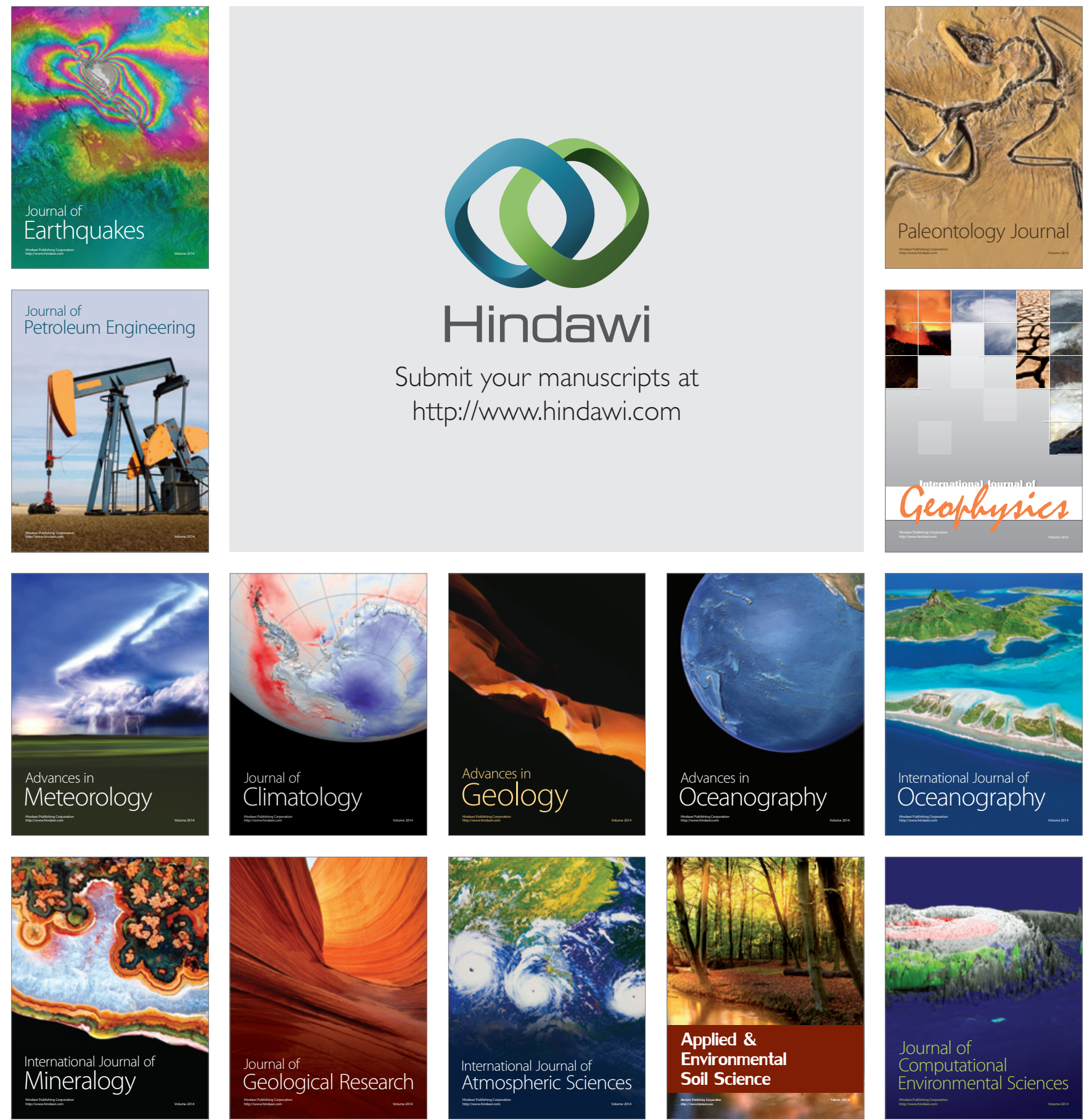